Check for updates

Cite this: RSC Adv., 2019, 9, 2703

Received 9th November 2018 Accepted 7th January 2019

DOI: 10.1039/c8ra09269a

rsc.li/rsc-advances

\section{Synthesis of 4-(1H-isochromen-1-yl)isoquinolines through the silver-catalysed homodimerization of ortho-alkynylarylaldehydes and subsequent condensation of the 1,5-dicarbonyl motif with $\mathrm{NH}_{3} \dagger$}

\author{
Minghui Guo, ${ }^{a}$ Xin Meng, ${ }^{\text {*a }}$ Yang Zhao, ${ }^{a}$ Yuexia Dong, ${ }^{a}$ Xuejun Sun, ${ }^{a}$ Laijin Tian*ab \\ and Ziping $\mathrm{CaO}$ (iD)*ab
}

4-(1H-Isochromen-1-yl)isoquinoline derivatives were synthesized in high yields via the $\mathrm{AgBF}_{4}$-catalyzed self-reaction of ortho-alkynylarylaldehydes to give isochromene intermediates, followed by the dehydration of the 1,5-dicarbonyl motif with $\mathrm{NH}_{3}$. Compared with electron-rich aromatic substituents, this strategy can provide the desired isochromene products with an electron-deficient isoquinoline unit. The reactions feature simple experimental operations, mild reaction conditions and high product yields.

\section{Introduction}

The $1 H$-isochromene skeleton is the core structure of many biologically active molecules possessing important pharmaceutical activities, such as the those involved in the inflammatory activation of microglia, ${ }^{1}$ antimicrobial activity against the Gram-positive bacteria Staphylococcus aureus and Streptococcus pneumoniae, ${ }^{2}$ selective receptor antagonists of neurokinin-1 (NK1), ${ }^{3}$ and antagonists of Mycobacterium bovis BCG. ${ }^{4}$ Isoquinoline derivatives are also a class of important heterocycles having acetylcholinesterase inhibitory activities, ${ }^{5}$ murine tumor cell cytotoxicity, ${ }^{6}$ antiplasmodial activities, ${ }^{7}$ and so on. Thus, compounds with a combination of these two structural motifs could possess important potential bioactivity properties. Therefore, the synthesis of these kinds of product is of great significance.

Ortho-alkynylarylaldehydes are a class of important organic intermediates that can be converted into products possessing polycyclic skeletons. ${ }^{89}$ In particular, $1 H$-isochromenes can be readily constructed through metal- or non-metal-catalyzed reactions. ${ }^{10-17}$ Pioneering work by Yamamoto and co-workers revealed a $\mathrm{Pd}(\mathrm{OAc})_{2}$-catalyzed reaction of enynals with alcohols to afford alkoxyl-substituted $1 H$-isochromenes. ${ }^{10 i}$ From that time on, many methods were developed to access $1 H^{-}$

${ }^{a}$ School of Chemistry and Chemical Engineering, Qufu Normal University, Qufu 273165, P. R. China. E-mail: caozp_qfnu@163.com; mengxin1108@163.com; laijintian@163.com

${ }^{b}$ Shandong Key Laboratory of Life-Organic Analysis, Key Laboratory of Pharmaceutical Intermediates and Analysis of Natural Medicine, Qufu 273165, P. R. China

$\dagger$ Electronic supplementary information (ESI) available: Experimental procedures and analysis data for new compounds. See DOI: 10.1039/c8ra09269a isochromene derivatives starting from ortho-alkynylarylaldehydes, with a series of nucleophilic reagents. ${ }^{8}$ Recently, electron-rich (hetero)arenes, such as alkoxylbenzenes and indoles, have been utilized as nucleophiles leading to the synthesis of functionalized $1 H$-isochromene compounds with high efficiency (Scheme 1(a)). ${ }^{17}$ However, electron-deficient heteroarene-substituted $1 H$-isochromenes could not be synthesized via direct methods due to weak nucleophilic abilities. In this context, and following our ongoing interest in the reactions of enynal substrates, ${ }^{17 a, 18,21 a, c}$ we envisaged that these heteroarene-substituted $1 H$-isochromenes could be obtained via indirect ways involving the late-stage synthesis of the cyclic skeletons. Herein, we provide an efficient strategy to achieve the synthesis of isoquinoline-substituted $1 \mathrm{H}$-isochromenes through a two-step route, which contains the $\mathrm{AgBF}_{4}$-catalyzed self-reaction of ortho-alkynylarylaldehydes to give intermediate

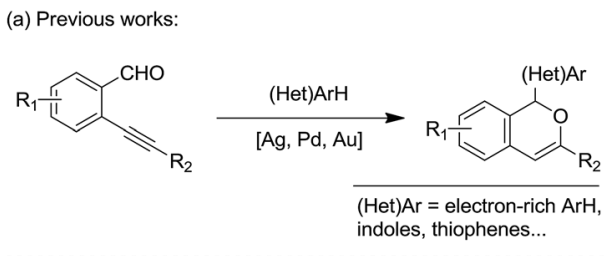

(b) This work:

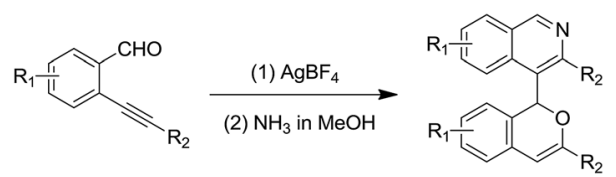

Scheme 1 Access to (hetero)aromatic substituted $1 \mathrm{H}$-isochromene derivatives. 
isochromenes with a 1,5-dicarbonyl motif followed by dehydration with $\mathrm{NH}_{3}$ to form the isoquinoline skeleton (Scheme 1(b)). It should be mentioned that the homodimerization of ortho-alkynylarylaldehydes was discovered by Porco Jr et al. in 2007, while only one example was provided for forming the isochromene efficiently. ${ }^{13 c}$ The present study exhibited better substrate compatibility and the efficient synthesis of isoquinoline-substituted $1 H$-isochromenes. Furthermore, the reactions feature mild reaction conditions, simple operation procedures and high efficiency.

\section{Results and discussion}

We started from a dimerized product 2 , which has a $1 H$-isochromene ring and a 1,5-dicarbonyl motif. Compound 2 can be obtained in $80 \%$ yield as a mixture of two diastereoisomers ( $\mathrm{dr}$ $=1 / 1$ (ref. 19)) through the self-reaction of the ortho-alkynylbenzaldehyde 1a under conditions involving the presence of silver salt $\left(\mathrm{AgBF}_{4} ; 10 \mathrm{~mol} \%\right)$ with 1,2-dichloroethane (DCE) as the solvent (Table 1, entry 1). Notably, the two isomers of 2 can be isolated carefully via column chromatography. In order to further improve the yield of 2, a series of metal salts were screened (Table 1, entries 2-8). The results showed that $\mathrm{AgBF}_{4}$ was the optimal catalyst. Other silver salts such as $\mathrm{AgSbF}_{6}$ and

Table 1 Optimization of the conditions for the homodimerization of $1 a^{a}$

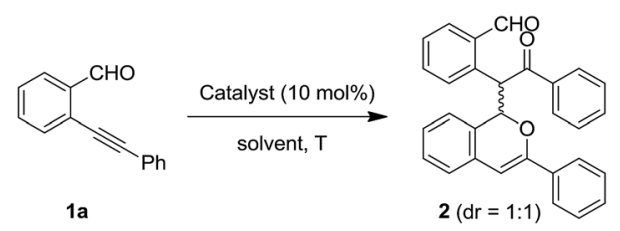

\begin{tabular}{|c|c|c|c|c|}
\hline Entry & Catalyst & Solv. & Temp. $\left({ }^{\circ} \mathrm{C}\right)$ & Yield $^{b}(\%)$ \\
\hline 1 & $\mathrm{AgBF}_{4}$ & DCE & 15 & 80 \\
\hline 2 & $\mathrm{AgSbF}_{6}$ & DCE & 15 & 0 \\
\hline 3 & $\mathrm{AgNO}_{3}$ & DCE & 15 & 0 \\
\hline 4 & AgOTf & DCE & 15 & 66 \\
\hline 5 & $\mathrm{CuI}$ & DCE & 15 & 0 \\
\hline 6 & $\mathrm{ZnCl}_{2}$ & DCE & 15 & 0 \\
\hline 7 & $\mathrm{ZnBr}_{2}$ & DCE & 15 & 0 \\
\hline 8 & $\mathrm{Pd}(\mathrm{OAc})_{2}$ & DCE & 15 & 71 \\
\hline 9 & $\mathrm{AgBF}_{4}$ & DCM & 15 & 73 \\
\hline 10 & $\mathrm{AgBF}_{4}$ & THF & 15 & 89 \\
\hline 11 & $\mathrm{AgBF}_{4}$ & $\mathrm{CH}_{3} \mathrm{CN}$ & 15 & 76 \\
\hline 12 & $\mathrm{AgBF}_{4}$ & 1,4-Dioxane & 15 & 84 \\
\hline 13 & $\mathrm{AgBF}_{4}$ & THF & 0 & 85 \\
\hline 14 & $\mathrm{AgBF}_{4}$ & THF & 25 & 93 \\
\hline 15 & $\mathrm{AgBF}_{4}$ & THF & 45 & 91 \\
\hline 16 & $\mathrm{AgBF}_{4}$ & THF & 60 & 91 \\
\hline $17^{c}$ & $\mathrm{AgBF}_{4}$ & Dry THF & 25 & 68 \\
\hline $18^{c, d}$ & $\mathrm{AgBF}_{4}$ & Dry THF & 25 & 92 \\
\hline 19 & - & THF & 100 & 0 \\
\hline
\end{tabular}

${ }^{a}$ All reactions were carried out with $1 \mathrm{a}(0.4 \mathrm{mmol})$ and catalyst $(0.04 \mathrm{mmol}, 0.1$ equiv.) in the indicated solvent $(1.6 \mathrm{~mL})$ under air for about 7 and 8 hours. ${ }^{b}$ The yield of isolated products. ${ }^{c}$ Under an $\mathrm{N}_{2}$ atmosphere. ${ }^{d} 1$ equiv. of $\mathrm{H}_{2} \mathrm{O}$ was added.
$\mathrm{AgNO}_{3}$ couldn't afford product 2 at all, whereas the use of an AgOTf catalyst could lead to the formation of 2 in $66 \%$ yield (Table 1, entries 2-4). Copper(I) and zinc(II) catalysts showed no catalytic reactivity under the presented conditions (Table 1, entries 5-7). Notably, $\mathrm{Pd}(\mathrm{OAc})_{2}$ could promote the formation of product 2 , albeit with a slightly lower yield (Table 1, entry 8 ). Subsequently, several solvents were investigated, revealing that tetrahydrofuran (THF) was suitable for the present transformation and the yield of 2 could be improved to $89 \%$ (Table 1 , entries 9-12). Furthermore, the temperature effects indicated that the homodimerization product 2 could be readily obtained in 91-93\% yield when the reaction was carried out at room temperature or under heating (Table 1, entries 14-16), while lowering the temperature to $0{ }^{\circ} \mathrm{C}$ led to a slightly lower yield (Table 1, entry 13). In order to consider the water effect, control experiments were carried out. The use of completely dry THF led to a low yield of 2 under an $\mathrm{N}_{2}$ atmosphere (Table 1, entry 17). The addition of water (such as 1.0 equiv.) into dry THF did not obviously influence the reaction (Table 1 , entry 18 ). In addition, the reaction couldn't proceed at $100{ }^{\circ} \mathrm{C}$ in the absence of $\mathrm{AgBF}_{4}$ (Table 1 , entry 19). So, the final conditions were established as those shown by entry 14 in Table 1 .

To achieve the cyclization of the 1,5-dicarbonyl motif of compound 2 to an isoquinoline skeleton, different nitrogen sources and reaction conditions were investigated, and these are shown in Table 2. It could be found that the use of $\mathrm{NH}_{3}$ solution in $\mathrm{MeOH}$ proved to be suitable, affording the desired product $3 \mathrm{a}$ in $62 \%$ yield with the decomposed product 4 present in $20 \%$ yield (Table 2, entry 3 ). Other nitrogen sources such as $\mathrm{NH}_{4} \mathrm{OAc}$ and $\mathrm{NH}_{3} \cdot \mathrm{H}_{2} \mathrm{O}$ could lead to the formation of $3 \mathbf{a}$ but with more side-product 4 (Table 2, entries 1 and 2). Temperature studies showed that the cyclized product 3 a could be

Table 2 Optimization of the conditions for the condensation of 1,5dicarbonyl 2 with $\mathrm{NH}_{3}{ }^{a}$

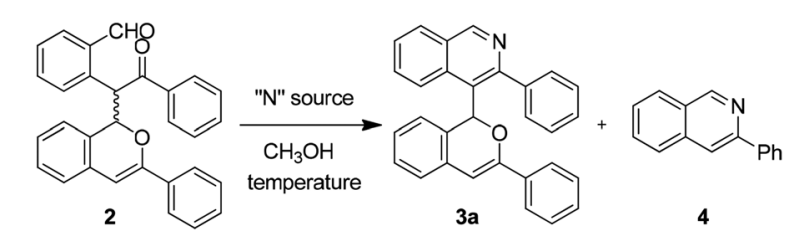

\begin{tabular}{llllr}
\hline & & & \multicolumn{2}{c}{ Yield $^{b}(\%)$} \\
\cline { 3 - 5 } Entry & "N" source (equiv.) & Temp. $\left({ }^{\circ} \mathrm{C}\right)$ & $3 \mathbf{3}$ & $\mathbf{4}$ \\
\hline 1 & $\mathrm{NH}_{4} \mathrm{OAc}(3)$ & 50 & 32 & 73 \\
2 & $\mathrm{NH}_{3} \cdot \mathrm{H}_{2} \mathrm{O}(3)$ & 50 & 47 & 50 \\
3 & $\mathrm{NH}_{3}$ in $\mathrm{CH}_{3} \mathrm{OH}(3)$ & 50 & 62 & 20 \\
4 & $\mathrm{NH}_{3}$ in $\mathrm{CH}_{3} \mathrm{OH} \mathrm{(3)}$ & 40 & 75 & 14 \\
5 & $\mathrm{NH}_{3}$ in $\mathrm{CH}_{3} \mathrm{OH} \mathrm{(3)}$ & 25 & 87 & 7 \\
6 & $\mathrm{NH}_{3}$ in $\mathrm{CH}_{3} \mathrm{OH} \mathrm{(3)}$ & 0 & 82 & 7 \\
7 & $\mathrm{NH}_{3}$ in $\mathrm{CH}_{3} \mathrm{OH}(1.5)$ & 25 & 93 & - \\
8 & $\mathrm{NH}_{3}$ in $\mathrm{CH}_{3} \mathrm{OH} \mathrm{(1.0)}$ & 25 & 75 & 8
\end{tabular}

${ }^{a}$ All reactions were carried out with $2(0.2 \mathrm{mmol})$ and the nitrogen source $(0.2-0.6 \mathrm{mmol}, 1.0-3.0$ equiv.) in methanol $(1.6 \mathrm{~mL})$ at the indicated temperature for about 12 hours. ${ }^{b}$ The yield of isolated products based on 2 . 


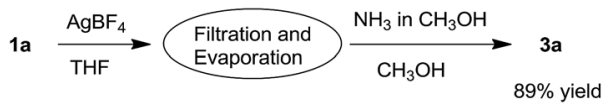

Scheme 2 The convenient synthesis of the 4-(1H-isochromen-1-yl) isoquinoline $3 a$.

obtained in $87 \%$ yield with a lower amount of 4 under room temperature conditions (Table 2, entry 5). In addition, lowering the loading of $\mathrm{NH}_{3}$ solution in $\mathrm{MeOH}$ could also add to the yield of $3 \mathbf{a}$ to $93 \%$, with trace amounts of side-product 4 (Table 2, entry 7).

The one-pot synthesis of the isoquinoline 3a with an isochromene unit was also subsequently examined. The $\mathrm{AgBF}_{4}$ catalyzed self-reaction was accomplished and the $\mathrm{NH}_{3}$ source was then injected in a straightforward manner, affording the final product $3 \mathbf{a}$ in only $31 \%$ yield. To our delight, after the filtration of the metal salt and the evaporation of solvent following the first reaction, the residue was dissolved in methanol and the $\mathrm{NH}_{3}$ source was then added to provide the isoquinoline 3a with higher efficiency (Scheme 2). The low yield for the direct one-pot reaction may be owing to the use of an improper solvent for the second step.

With the optimal process for the synthesis of $\mathbf{3 a}$ in hand, the scope of ortho-alkynylarylaldehyde substrates was next investigated (Table 3 ). It could be found that a variety of ortho-alkynylbenzaldehyde derivatives could be applied to the present reaction, leading to the synthesis of the $4-(1 H$-isochromen-1-yl $)$ isoquinolines $\mathbf{3 a - p}$ in $31-91 \%$ yields. The substrates $\mathbf{1 b}-\mathbf{c}$, having an electron-rich group at the para-position of the alkynylaryl part, were suitable for this transformation, giving the corresponding products $\mathbf{3 b}$-c with good efficiency. The halosubstituted (F, Cl and $\mathrm{Br}$ ) phenylethynylbenzaldehydes 1d-f could be also converted to the desired isoquinolines 3d-f efficiently. The substrate $\mathbf{3 g}$, with an electron-deficient cyano group, could afford the desired isoquinoline $\mathbf{3 g}$, albeit with a low yield. The meta-substituted-phenylethynylbenzaldehydes $\mathbf{1 h}-\mathbf{j}$ were also good substrates, leading to the formation of the 4 -( $1 H$-isochromen-1-yl)isoquinolines $\mathbf{3 h}-\mathbf{j}$ in $70-86 \%$ yields. In addition, the alkynylarylaldehydes $1 \mathbf{k}-\mathbf{p}$, having groups with different electronic natures in the arylaldehyde part, could generate efficiently the cyclized products $3 \mathbf{k}-\mathbf{p}$ under the current conditions. Alkyl-substituted-alkynylbenzaldehydes such as 1q were also examined. However, the synthesis of the desired polycycle $\mathbf{3 q}$ was not observed.

A possible mechanism for the synthesis of the isoquinoline 3a is proposed in Scheme 3. ${ }^{\mathbf{1 3 c}}$ The coordination of the alkyne motif of 1a to a silver(I) cation could give complex A, which then undergoes 6-endo-dig cycloisomerization to form the vinyl metal benzopyrylium $\mathbf{B}$. The exo[3+2]-cycloaddition of $\mathbf{B}$ could afford the polycyclic intermediate $\mathbf{D}$ via $\mathbf{C .}^{\mathbf{2 0 , 2 1}}$ The isomerization of the double bonds of $\mathbf{D}$ with the departure of $\mathrm{Ag}(\mathrm{I})^{+}$(or $\mathrm{H}^{+}$) leads to the formation of intermediate $\mathbf{E}$, followed by fragmentation to yield the oxonium species $\mathbf{F}^{22}$ The addition of water to the oxonium $\mathbf{F}$ and its protodemetalation could form the hemiketal G, which could be converted to the ketoaldehyde product 2 via
Table 3 Scope of substrates ${ }^{a, b}$
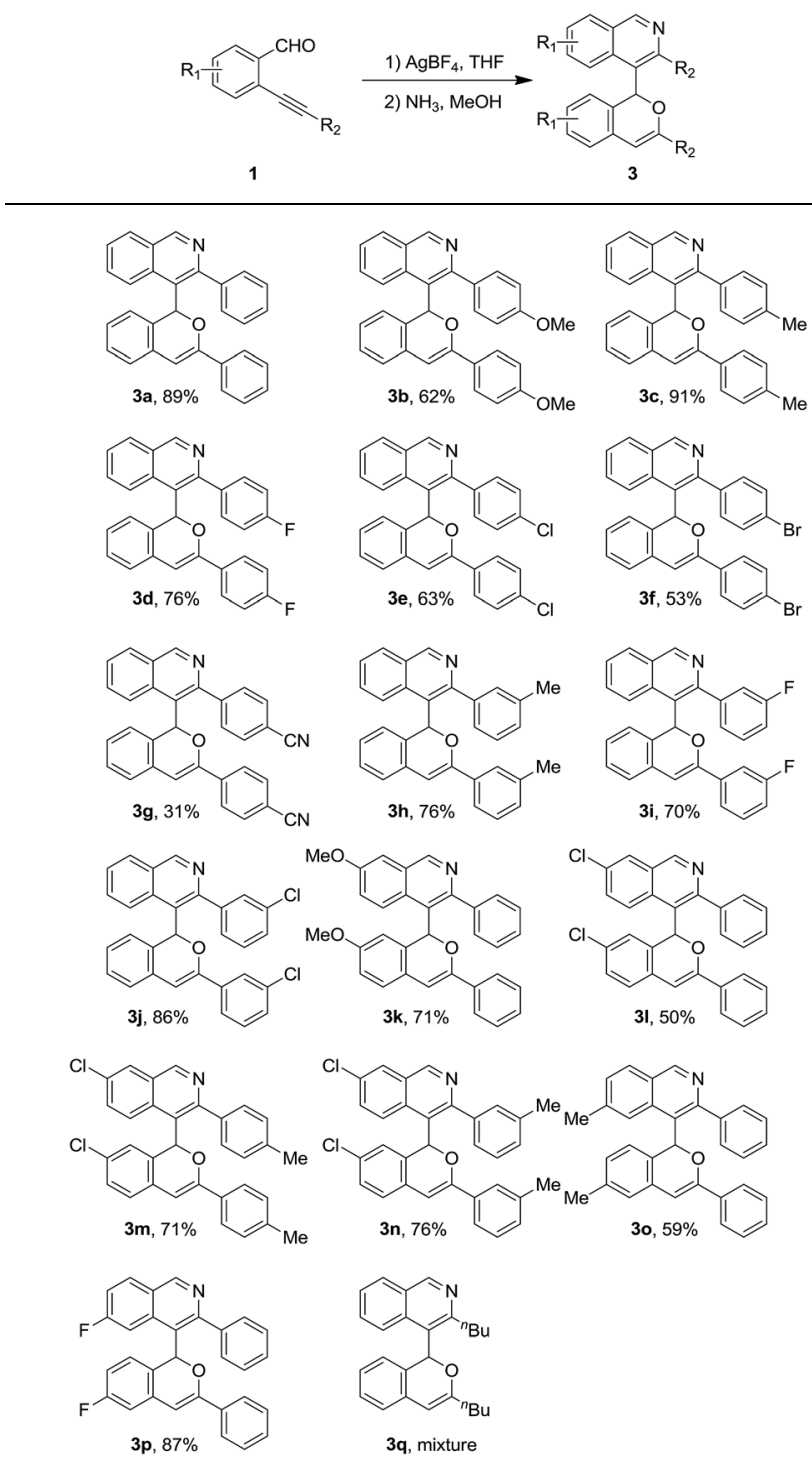

${ }^{a}$ See the Experimental section. ${ }^{b}$ The yield of isolated products.
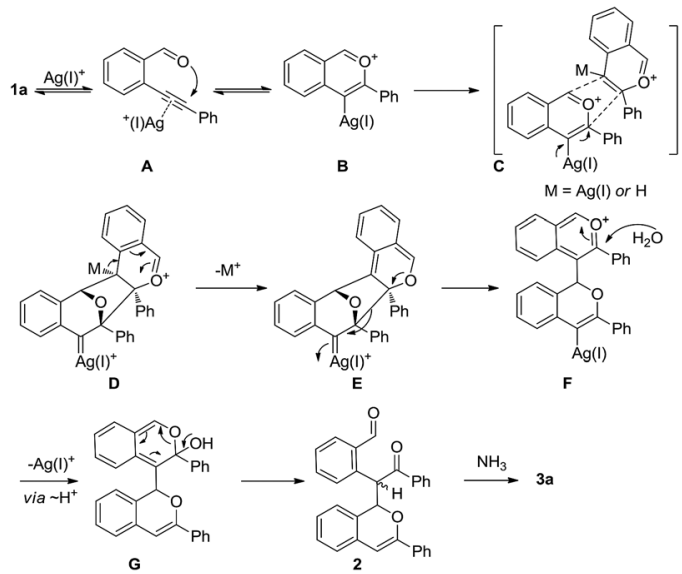

Scheme 3 The proposed mechanism for the formation of $3 a$. 


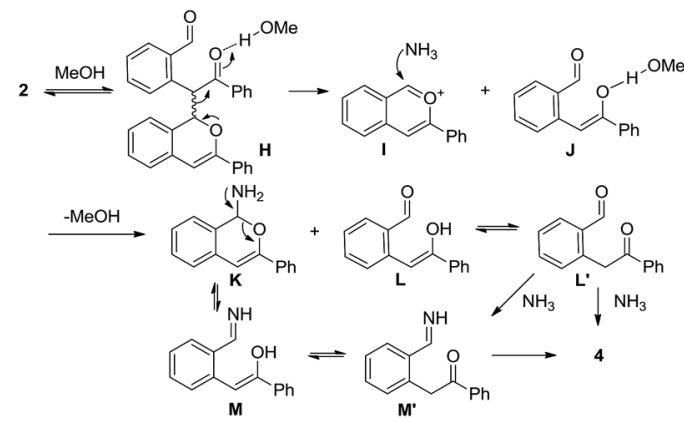

Scheme 4 The proposed mechanism for the formation of the sideproduct 4 .

aromatization. The condensation of the 1,5-dicarbonyl motif of 2 with $\mathrm{NH}_{3}$ could afford the final isoquinoline product $\mathbf{3 a}$.

Scheme 4 outlines a proposed pathway for the formation of the isoquinoline 4 . The homodimer 2 could give species $\mathbf{H}$ through the solvation of methanol to activate the ketocarbonyl, followed by fragmentation (retro-aldol type reaction) to yield the benzopyrylium $\mathbf{I}$ and species $\mathbf{J}{ }^{23}$ The addition of $\mathrm{NH}_{3}$ to $\mathbf{I}$ and the desolvation of $\mathbf{J}$ could afford the intermediates $\mathbf{K}$ and $\mathbf{L}$, respectively. The fragmentation of the $\mathrm{N}, \mathrm{O}$-acetal $\mathbf{K}$ could give $\mathbf{M}$ (or the tautomer $\mathbf{M}^{\prime}$ ), leading to the formation of $\mathbf{4}$ through dehydration. Furthermore, the condensation of $\mathbf{L}$ (or the tautomer $\mathbf{L}^{\prime}$ ) with $\mathrm{NH}_{3}$ via the intermediate $\mathbf{M}^{\prime}$ affords the final isoquinoline 4.

\section{Experimental}

\section{Representative procedure for the synthesis of $4-(1 \mathrm{H}-$ isochromen-1-yl)isoquinolines}

To a stirred solution of the ortho-alkynylbenzaldehyde 1a (82.5 mg, $0.4 \mathrm{mmol}, 1.0$ equiv.) in THF (1.6 mL), $\mathrm{AgBF}_{4}(7.8 \mathrm{mg}$, $0.04 \mathrm{mmol}, 0.1$ equiv.) was added at room temperature. The reaction proceeded for about 8 hours. The mixture was filtered using a short silica gel column and volatiles were then evaporated off. The resulting crude 1,5-dicarbonyl 2 was dissolved in methanol $(1.6 \mathrm{~mL})$, followed by the injection of a solution of $\mathrm{NH}_{3}$ in methanol $\left(0.15 \mathrm{~mL}, 2.0 \mathrm{~mol} \mathrm{~L}^{-1}, 1.5\right.$ equiv.). The mixture was then stirred at room temperature for about 12 hours. After the evaporation of the solvent, the residue was then subjected to column chromatography to afford the desired isoquinoline $\mathbf{3 a}$.

\section{Conclusions}

In summary, we have developed a new method to prepare 4-( $1 \mathrm{H}^{-}$ isochromen-1-yl)isoquinoline derivatives in high yields. This method contains two reactions involving the silver-catalyzed self-reaction of ortho-alkynylarylaldehydes and the subsequent condensation of the 1,5-dicarbonyl motif with $\mathrm{NH}_{3}$, without the chromatographic purification of the intermediates. Notably, this method could provide the desired isochromene products with an electron-deficient isoquinoline unit, which can't be obtained through the direct reaction of isoquinolines with ortho-alkynylarylaldehydes. Further work will focus on potential bioactivity studies of these heterocycles.

\section{Conflicts of interest}

There are no conflicts to declare.

\section{Acknowledgements}

We are grateful to the NSFC (21402106), the Shandong Natural Science Foundation (ZR2018JL013 and ZR2014BQ024), and the Research Start-up Foundation of Qufu Normal University (bsqd20130115).

\section{Notes and references}

1 A. R. Togna, V. Latina, G. Trefiletti, M. Guiso, S. Moschini and G. I. Togna, Brain Res. Bull., 2013, 95, 33.

2 Y. Li, S. Niu, B. Sun, S. Liu, X. Liu and Y. Che, Org. Lett., 2010, $12,3144$.

3 Y. Shishido, H. Wakabayashi, H. Koike, N. Ueno, S. Nukui, T. Yamagishi, Y. Murata, F. Naganeo, M. Mitzutani, K. Shimada, Y. Fujiwara, A. Sakakibara, O. Suga, R. Kusano, S. Ueda, Y. Kanai, M. Tsuchiya and K. Satake, Biomed. Chem., 2008, 16, 7193.

4 C. W. Brown, S. Liu, J. Klucik, K. D. Berlin, P. J. Brennan, D. Kaur and D. M. Benbrook, J. Med. Chem., 2004, 47, 1008.

5 J. Zhang, Q.-Y. Zhang, P.-F. Tu, F.-C. Xu and H. Liang, J. Nat. Prod., 2018, 81, 364.

6 D. J. Milanowski, K. R. Gustafson, J. A. Kelley and J. B. McMahon, J. Nat. Prod., 2004, 67, 70.

7 C. W. Wright, S. J. Marshall, P. F. Russell, M. M. Anderson, D. Phillipson, G. C. Kirby, D. C. Warhurst and P. L. Schiff Jr., J. Nat. Prod., 2000, 63, 1638.

8 For leading reviews on the reactions of enynal substrates, see: (a) L. Chen, K. Chen and S. Zhu, Chem, 2018, 4, 1208; (b) J. Ma, L. Zhang and S. Zhu, Curr. Org. Chem., 2016, 20, 102; (c) A. L. S. Kumari, A. S. Reddy and K. C. K. Swamy, Org. Biomol. Chem., 2016, 14, 6651; (d) H. Wang, Y. Kuang and J. Wu, Asian J. Org. Chem., 2012, 1, 302; (e) N. T. Patil and Y. Yamamoto, ARKIVOC, 2007, 5, 6; (f) N. Asao, Synlett, 2006, 1645.

9 For recent examples, see: (a) H. Luo, R. Liang, L. Chen, H. Jiang and S. Zhu, Org. Chem. Front., 2018, 5, 1160; (b) M. Michalska, K. Grudzień, P. Małecki and K. Grela, Org. Lett., 2018, 20, 954; (c) C. R. Reddy and K. Mallesh, Org. Lett., 2018, 20, 150; (d) X. Zhang, C. Lyu, P. Li, W. Yong, J. Li and X. Zhu, Chin. J. Org. Chem., 2018, 38, 208; (e) S. Qiu, L. Chen, H. Jiang and S. Zhu, Org. Lett., 2017, 19, 4540; (f) W.-J. Hao, Y. Du, D. Wang, B. Jiang, Q. Gao, S.-J. Tu and G. Li, Org. Lett., 2016, 18, 1884; $(g)$ T. Arto, P. Fernández, F. J. Fañanás and F. Rodríguez, Chem. Commun., 2016, 52, 13405.

10 For examples with oxygen nucleophiles: (a) S. Handa and L. M. Slaughter, Angew. Chem., Int. Ed., 2012, 51, 2912; (b) L.-P. Liu and G. B. Hammond, Org. Lett., 2010, 12, 4640; (c) A. Kotera, J. I. Uenishi and M. Uemura, Tetrahedron Lett., 2010, 51, 1166; (d) T. Godet, C. Vaxelaire, C. Michel, A. Milet and P. Belmont, Chem.-Eur. J., 2007, 13, 5632; (e) N. T. Patil and Y. Yamamoto, J. Org. Chem., 2004, 69, 5139; 
(f) D. Yue, N. D. Cá and R. C. Larock, Org. Lett., 2004, 6, 1581; (g) S. Mondal, T. Nogami, N. Asao and Y. Yamamoto, J. Org. Chem., 2003, 68, 9496; (h) J. Barluenga, H. V. Villa, A. Ballesteros and J. M. González, J. Am. Chem. Soc., 2003, 125, 9028; (i) N. Asao, T. Nogami, K. Takahashi and Y. Yamamoto, J. Am. Chem. Soc., 2002, 124, 764.

11 For examples with nitrogen nucleophiles: (a) A. K. Verma, D. Choudhary, R. K. Saunthwal, V. Rustagi, M. Patel and R. K. Tiwari, J. Org. Chem., 2013, 78, 6657; (b) G. Dyker, D. Hildebrandt, J. Liu and K. Merz, Angew. Chem., Int. Ed., 2003, 42, 4399.

12 For examples with phosphite nucleophiles: X. Yu, Q. Ding, W. Wang and J. Wu, Tetrahedron Lett., 2008, 49, 4390.

13 For examples with activated methylene nucleophiles: (a) D. Malhotra, L.-P. Liu, M. S. Mashuta and G. B. Hammond, Chem.-Eur. J., 2013, 19, 4043; (b) S. Obika, H. Kono, Y. Yasui, R. Yanada and Y. Takemoto, J. Org. Chem., 2007, 72, 4462; (c) A. B. Beeler, S. Su, C. A. Singleton and J. A. Porco Jr., J. Am. Chem. Soc., 2007, 129, 1413.

14 For examples with terminal alkyne nucleophiles: X. Yao and C.-J. Li, Org. Lett., 2006, 8, 1953.

15 For examples with allylsilane nucleophiles: (a) S. Bhunia, K.-C. Wang and R.-S. Liu, Angew. Chem., Int. Ed., 2008, 47, 5063; (b) N. Asao, C. S. Chan, K. Takahashi and Y. Yamamoto, Tetrahedron, 2005, 61, 11322.

16 For examples with hydride nucleophiles: (a) E. TomásMendivil, J. Starck, J.-C. Ortuno and V. Michelet, Org. Lett., 2015, 17, 6126; (b) M. Terada, F. Li and Y. Toda, Angew. Chem., Int. Ed., 2014, 53, 235; (c) K. Saito, Y. Kajiwara and T. Akiyama, Angew. Chem., Int. Ed., 2013, 52, 13284.

17 For examples with (hetero)arene nucleophiles: (a) H. Zhu, X. Meng, Z. Cao, G. Chen, X. Sun and J. You, Synth. Commun., 2017, 47, 463; (b) G. Mariaule, G. Newsome, P. Y. Toullec, P. Belmont and V. Michelet, Org. Lett., 2014, 16, 4570; (c) H. Wang, X. Han and X. Lu, Chin. J. Chem., 2011, 29, 2611; (d) B. Ouyang, J. Yuan, Q. Yang, Q. Ding, Y. Peng and J. Wu, Heterocycles, 2011, 82, 1239; (e) R.-Y. Tang and J.-H. Li, Chem.-Eur. J., 2010, 16, 4733; (f)
J. Barluenga, V.-V. Henar, I. Merino, A. Ballesteros and J. M. González, Chem.-Eur. J., 2006, 12, 5790; $(g)$ D. Yue, N. D. Cá and R. C. Larock, J. Org. Chem., 2006, 71, 3381.

18 For selected examples: (a) X. Meng, H. Zhu, G. Chen, L. Tian, X. Sun, Z. Cao and J. You, Asian J. Org. Chem., 2017, 6, 921; (b) R. Zhang, H. Zhu, X. Meng, Z. Cao, G. Chen, L. Tian, X. Sun and J. You, Eur. J. Org. Chem., 2017, 2615; (c) H. Zhu, Z. Cao, X. Meng, L. Tian, G. Chen, X. Sun and J. You, Tetrahedron, 2017, 73, 3310; (d) Z. Cao, H. Zhu, X. Meng, J. Guan, Q. Zhang, L. Tian, X. Sun, G. Chen and J. You, Chem.-Eur. J., 2016, 22, 16979; (e) Z. Cao, R. Zhang, X. Meng, H. Li, J. Li, H. Zhu, G. Chen, X. Sun and J. You, RSC Adv., 2016, 6, 74582; $(f)$ Z. Cao, H. Zhang, X. Zhang, L. Zhang, X. Meng, G. Chen, X.-E. Zhao, X. Sun and J. You, RSC Adv., 2015, 5, 103155.

19 The dr value of 2 was determined by ${ }^{1} \mathrm{H}$ NMR analysis of crude reaction mixtures.

20 The intermediate $\mathbf{B}$ could be very prone to protodemetalation, also see (a) J. T. R. Liddon, M. J. James, A. K. Clarke, P. O'Brien, R. J. K. Taylor and W. P. Unsworth, Chem.-Eur. J., 2016, 22, 8777; (b) J. T. R. Liddon, J. A. Rossi-Ashton, A. K. Clarke, J. M. Lynam, R. J. K. Taylor and W. P. Unsworth, Synthesis, 2018, 50, 4829.

21 For the case of carbenoid type intermediates, see ref. $13 c$, also,(a) Z. Cao, H. Zhu, X. Meng, L. Tian, X. Sun, G. Chen and J. You, Chem.-Eur. J., 2016, 22, 9125; (b) R. Liang, T. Ma and S. Zhu, Org. Lett., 2014, 16, 4412; (c) Z. Cao, H. Zhu, X. Meng, L. Tian, G. Chen, X. Sun and J. You, J. Org. Chem., 2016, 81, 12401.

22 Another possible mechanism involving the direct selfaddition of intermediate $\mathbf{B}$ (or protodemetalated type) to give $\mathbf{F}$ could not be ignored.

23 For leading examples on acid or solvent-promoted retroAldol reaction, see:(a) K. L. Ivanov, I. M. Vatsouro, S. I. Bezzubov, M. Y. Melnikov and E. M. Budynina, Org. Chem. Front., 2018, 5, 1655; (b) M. Sasaki, K. Goto, K. Tajima, T. Adschiri and K. Arai, Green Chem., 2002, 4, 285. 